\title{
Assessing the impact of a new delivery method of insulin on glycemic control using a novel trial design
}

\author{
Thomas Strack' \\ Luc Martinez ${ }^{2}$ \\ Stefano Del Prato 3 \\ Larry Blonde ${ }^{4}$ \\ Burkhard Göke ${ }^{5}$ \\ Vincent Woo ${ }^{6}$ \\ Ann Millward ${ }^{7}$ \\ Ramon Gomis ${ }^{8}$ \\ Bill Canovatchel' \\ David Lawrence' \\ Nick Freemantle 9 \\ On behalf of the \\ EXPERIENCE Trial Team
}

'Pfizer Inc., New York, NY, USA;

${ }^{2}$ Société Française de Médecine

Générale, Issy les Moulineaux,

France; ${ }^{3}$ University of Pisa,

Pisa, Italy; ${ }^{4}$ Ochsner Medical

Center, New Orleans, LO, USA;

${ }^{5}$ University of Munich, Munich,

Germany; ${ }^{6}$ Health Sciences Centre,

Winnipeg, Canada; ${ }^{7}$ Peninsula

Medical School, Plymouth, UK;

${ }^{8}$ University of Barcelona, Barcelona,

Spain; ' University of Birmingham,

Birmingham, UK
Correspondence: Nick Freemantle Professor of Clinical Epidemiology and Biostatistics, School + Health \& Population Sciences, Primary Care

Clinical Sciences Building, University of

Birmingham, Edgbaston, Birmingham

BI5 2TT, UK

$\mathrm{Tel}+44$ I2I $4 \mid 47943$

Fax +44 I2I 4 I 43353

Email n.freemantle@bham.ac.uk
Objective: The purpose of the trial was to examine the impact of inhaled human insulin (INH) on patient or physician willingness to adopt insulin after oral diabetes agent failure.

Research design and methods: The EXPERIENCE trial was a one-year randomized controlled trial conducted at primary, secondary and tertiary care facilities in Europe and North America. The primary study endpoint was difference in glycated hemoglobin $\left(\mathrm{A}_{1 \mathrm{c}}\right)$ between randomized groups at 26 weeks, and results from that phase have been reported previously. The present report concerns results from the second 26-week extension phase. We also consider the applicability of the design. The trial recruited 727 patients with type 2 diabetes mellitus who, prior to randomization, were using two or more oral diabetes agents and whose $\mathrm{A}_{1 \mathrm{c}}$ was $\geq 8.0 \%$. Patients were randomized to two treatment settings: Group 1 (usual care with the option of INH) or Group 2 (usual care only). Usual care included adjusting oral therapy (optimizing current regimen or adding/deleting agents) and/or initiating subcutaneous (SC) insulin.

Results: At baseline, insulin was initiated by more (odds ratio [OR] 6.0;95\% confidence interval $[\mathrm{CI}] 4.2$ to $8.8 ; \mathrm{P}<0.0001)$ patients in Group $1(86.2 \% ; 76.7 \% \mathrm{INH}$ plus $9.5 \% \mathrm{SC})$ than in Group $2\left(50.7 \%\right.$; SC insulin only). The largest reduction from baseline in $\mathrm{A}_{1 \mathrm{c}}$ was in Group $1(-2.0 \pm 1.2 \%)$ at Week 12 and in Group $2(-1.8 \pm 1.3 \%)$ at Week $26(\mathrm{P}=0.003)$. At 52 weeks, $79.8 \%$ were on insulin in Group $1(67.4 \% \mathrm{INH} ; 12.4 \% \mathrm{SC}) \mathrm{vs} 58.1 \%$ (SC only) in Group 2, and mean (SD) changes in $\mathrm{A}_{1 \mathrm{c}}$ from baseline were $-1.9 \%(1.2 \%)$ and $-1.8 \%(1.3 \%)$ in Groups 1 and 2, respectively $(\mathrm{P}=0.05)$. Hypoglycemic event rates per patient month were 0.3 and 0.1 in Groups 1 and 2, respectively $(\mathrm{P}<0.0001)$.

Conclusion: The EXPERIENCE trial showed that novel delivery technology can accelerate the adoption of insulin although some attenuation of differences is observed over time. And further, that this was achieved in a population of patients who appeared more ready to move to insulin therapy than observed in standard clinical practice, and a group of physicians who appeared more ready to adopt INH than the majority of physicians.

Keywords: inhaled insulin, EXPERIENCE trial, diabetes, patient preference

\section{Introduction}

The burden of diabetes is attributable to the chronic conditions and complications of the disease, and continues to rise as a socioeconomic burden. ${ }^{1}$

Furthermore there is considerable evidence that improved blood glucose control in line with current guidelines in patients with type 2 diabetes decreases diabetic complications when insulin or insulin secretagogues, eg, sulfonylurea therapy, are used. ${ }^{2,3}$ Despite proven benefits insulin is often delayed in nonsevere patients and is rarely used as an alternative treatment. ${ }^{4}$ On one hand, patients delay insulin because of the lack of obvious symptoms; on the other hand physicians fear reducing the quality of life of patients when treating with insulin. ${ }^{5}$ A recent study on the development of a new self-administered questionnaire showed significant fears and barriers to insulin injections patients 
felt restricted because of self-surveillance and liberty loss, bothered by being seen while injecting insulin or skin marks at injection site, and stressed because of injection site pain. ${ }^{6}$ It has also been shown that treatment satisfaction accounted for patient preference for a particular insulin delivery system. ${ }^{7}$ Consequently, the need for more acceptable ways of insulin administration continues to motivate technical advances: injection devices that combine ultra-thin needles with dose administration convenience (multiple doses, dose accuracy, dose memory, less conspicuous pen-like appearance), development of long-acting insulin analogs for reduction of hypoglycemia and injection frequency, and, more recently, the search for alternate routes of administration such as pulmonary delivery. In a recent report for the National Health Service (NHS) in the UK, Horne suggested that taking medicine was a variable behavior that is influenced by patients' beliefs about their illness and treatment, but also by environmental factors including interactions with healthcare providers and the context of societal-policies and practice. ${ }^{8}$ More specifically concerning diabetes, Capelleri emphasized that treatment convenience, ease of use and social comfort contributed to patients' satisfaction with insulin delivery systems. ${ }^{9}$

Conventionally-designed trials where all subjects are randomized to only one intervention per study arm are likely to fail the goal to estimate adequately the impact of preference and acceptance of new technologies on biologic outcome measures such as $A_{1 c}$. Thus, to incorporate the effects of physician and patient preference, we designed a trial where both were able to choose between treatment options regardless of randomization. ${ }^{10,11}$ The EXPERIENCE study presented in this paper was designed to establish whether patients' acceptance of insulin translates into improved glycaemic control upon introduction of an inhaled insulin delivery system. The results from the initial 26-week period demonstrated ${ }^{12}$ that, at baseline, insulin was initiated by more patients in Group where inhaled insulin was available, and that mean (SD) changes in $A_{1 c}$ from baseline were greater in this group than in Group with standard care only (adjusted treatment difference $0.2 \%$; $\mathrm{P}=0.004)$. In the present paper we will discuss results from the second 26-week period as well as lessons learned from this novel study design concept.

\section{Methods}

This trial was a 52 week-long, open, randomized (1:1), parallel, multicenter study with a two-week run-in period. Stratification by previous diabetes treatment (ie, either two oral hypoglycemic agents (OAs) or three or more OAs) was employed. The study period between weeks 0 and 26 assessed the primary efficacy endpoint $\left(A_{1 c}\right)$ whereas the study period from week 26 to week 52 was considered an extended treatment period. There were two randomized treatment groups: Group 1 consisted of subjects who were given the option to choose inhaled insulin treatment while Group 2 subjects did not have the option of inhaled insulin. Irrespective of the availability of inhaled insulin, any subject could choose to remain on their current treatment or start any other marketed treatment (eg, subcutaneous [SC] insulin, OAs) in agreement with their study physician. Importantly, the initial treatment decisions could be re-visited and changed either at any time in the event of significant adverse drug reactions, or every three months in the event diabetes control remained unsatisfactory in the opinion of the treating physician, or at 26 weeks for any other reason, eg, incompatibility with life style. Thus, unlike most other trials, this study design incorporated drug choice and change as "real world" factors thus permitting optimization of treatments beyond dose.

Secondary outcomes included the uptake of insulin therapy, the number of subjects achieving specified glycaemic control, fasting glucose and lipid levels, Diabetes Treatment Satisfaction Questionnaire (DTSQ), and Euroqol (EQ-5D) generic health status measures.

For the purpose of this study, a hypoglycemic episode was defined as one of the following:

1. Characteristic symptoms of hypoglycemia (both neurological and nonneurological) with no blood glucose check that promptly resolve with food intake, subcutaneous glucagon, or intravenous glucose.

2. Characteristic symptoms of hypoglycemia together with blood glucose check showing values of $59 \mathrm{mg} / \mathrm{dL}$ (3.3 mmol/L) or less.

3. Any blood glucose measurement $49 \mathrm{mg} / \mathrm{dL}(2.7 \mathrm{mmol} / \mathrm{L})$ or less, with or without symptoms.

Every hypoglycemic event had to be characterized with respect to severity. In order to characterize the event as severe, all three of the following criteria had to be met:

1. The patient was unable to treat him/herself, and

2. The patient exhibited at least one of the following neurological symptoms:
1. Memory loss
2. Confusion
3. Uncontrollable behavior
4. Irrational behavior
5. Unusual difficulty in awakening
6. Suspected seizure
7. Seizure
8. Loss of consciousness, and

3. Either: 
- blood glucose was measured to be $49 \mathrm{mg} / \mathrm{dL}(2.7 \mathrm{mmol} / \mathrm{L})$ or less

or:

- If the blood glucose was not measured, the clinical manifestations were reversed by oral carbohydrates, subcutaneous glucagon, or intravenous glucose.

Events that do not meet all three criteria for severe hypoglycemia were characterized as "mild to moderate."

While all patients had to undergo pulmonary function testing (forced expiratory volume in one second $\left[\mathrm{FEV}_{1}\right]$, carbon monoxide diffusing capacity [DLco]) prior to randomization and at Week 52 (or end of study), only subjects who started INH were required to have additional tests at Week 12 , or more often depending on test results at Week 12 or in case of respiratory symptoms. Insulin antibody titers were assessed at baseline, week 26, and week 52 in all subjects.

\section{Statistical methods}

We hypothesized that insulin would be the major precursor to achieving a clinically important benefit in $\mathrm{A}_{1 \mathrm{c}}$ in subjects recruited to the trial, and that the availability of INH would lead to a difference in at least the initial uptake of insulin between the groups. Consequently the power calculation was based upon the expected difference in $\mathrm{A}_{1 \mathrm{c}}$ between the groups derived from anticipated differences in insulin use.

There were no studies in the literature to facilitate the estimation of the expected minimum difference between treatment groups for this type of study design in which patients are randomized to one of two treatment groups and then choose from several available treatments. The only data available to estimate the minimum difference between treatment groups were from a questionnaire-based feasibility study ${ }^{13}$ in which patients were randomized to these two choice groups and asked to indicate on a questionnaire what treatment option they would be willing to choose. In order to estimate the expected reduction in $\mathrm{A}_{1 \mathrm{c}}$ for each treatment group, estimates had first to be obtained for the percentages of patients who will choose each of the potential treatment options within each group. In the feasibility study, patients in the INH group indicated $40 \%$ would choose inhaled insulin, 10\% would choose SC insulin, 20\% would modify their oral regimen, and $30 \%$ would make no change. In contrast, patients in the control group indicated 14\% would choose SC insulin, $36 \%$ would prefer a modification of their oral treatment, while the remaining 50\% would not change their treatment. These data provided new insight into patient preferences, but also had limitations as with any questionnaire study in which patients are indicating what they would hypothetically choose. The expected average reduction in $\mathrm{A}_{1 \mathrm{c}}$ after one year of treatment for each of the possible choices had also to be estimated. Estimates for treatment-specific effects on the primary endpoint (reduction from baseline in $\mathrm{A}_{1 \mathrm{c}}$ ) were derived from review of the literature (INH: $1.5 \%$ to $1.9 \%$; SC insulin: 1.5 to $1.9 \%$; oral agents: 0 to 1.0$)$. Using both the possible range of biologic responses as well as a range of possible preferences for a given treatment option, we arrived at a range of possible trial outcomes suggesting that the most likely outcome would be a difference of $0.47 \%$ in the primary endpoint $A_{1 c}$. The sample size for the trial was thus estimated to require a minimum of 324 subjects per study arm to detect a mean difference of at least $0.4 \%$ between groups in the primary endpoint $A_{1 c}(\alpha=0.05, \beta=0.1)$ assuming that the standard deviation would not exceed $1.4 \%$ and the number of subjects dropping out would be less than $20 \%$.

\section{Results}

\section{Population}

Between April 15, 2004 and April 15, 2005, 1,137 subjects were screened. Of these, 727 met the eligibility criteria of the study, were randomized and received treatment. Patients were recruited in 109 centers (mean 6.8 patients per center; SD 5.6). Patient flow is described in Figure 1. Just under half of the randomized subjects were female (44\%). Overall, subjects had a mean age of 58.7 years and a mean BMI of $31 \mathrm{~kg} / \mathrm{m}^{2}$ (Table 1). Seventy three percent of subjects were taking two oral antidiabetic therapies at baseline, the remainder three or more. There were no major imbalances between groups at baseline with respect to demographic criteria or laboratory parameters (Table 1 ). The mean baseline $A_{1 c}(S D)$ was $9.3 \%(1.2 \%)$ in Group 1 and 9.2\% (1.1\%) in Group 2. There were subjects who prematurely discontinued from the study up to 12 October 2006 (last subject visit): 44 (12\%) subjects in Group 1, and 37 (10\%) subjects in Group 2. Of those, 18 subjects in each group withdrew because for nonstudyrelated reasons. Twelve subjects in Group 1 and 4 in Group 2 discontinued for adverse events.

\section{Preferences of patients Initial treatment}

Insulin was added to current diabetes therapy by $86 \%$ of patients in Group 1 at baseline (266 subjects [76.7\%] INH and 33 subjects [9.5\%] SC insulin alone), compared to 184 subjects (50.7\%) in Group 2 (odds ratio [OR] 6.0; 95\% confidence interval [CI] 34.2 to 8.8; $\mathrm{P}<0.0001$ ) (Figure 3). In Group 1, of those who adopted INH at baseline, 6 subjects $(1.7 \%)$ also added intermediate- or long-acting SC insulin. 


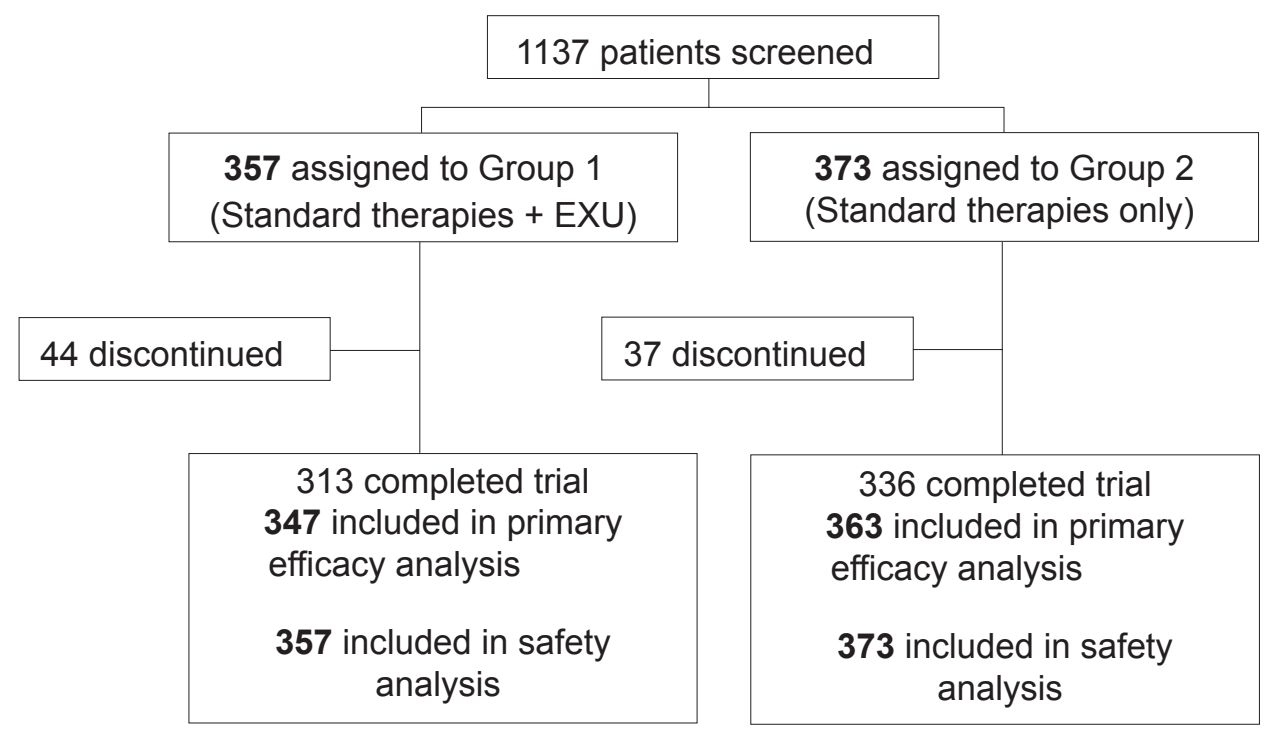

Figure I Patient disposition.

A total of 48 subjects in Group 1 were treated with oral agents alone including 25 (7.2\%) subjects who switched/added a new oral agent without insulin and $23(6.6 \%)$ subjects who optimized their current treatment regimen. By contrast, 59 subjects (16.3\%) in Group 2 did not add any new oral or insulin regimen at baseline and only optimized their current oral agent regimens. Another 120 subjects (33.1\%) added a new oral agent. The majority of subjects in Group 2 added a SC insulin regimen $(184 ; 50.7 \%)$.

\section{Subsequent treatment}

Subjects were able to change treatments at Weeks 12 or 34 where existing treatment proved ineffective, and at Week 26 for any reason. As a result, the number of subjects who had progressed to insulin increased in Group 1 by Week 26 to 273 (78.7\%) using INH and 37 (10.7\%) using SC insulin. However, as a results of treatment change decisions made at the Week 26 visit, the number of subjects remaining on INH fell to $250(70 \%)$ the same week, and by Week 52 to $234(67.4 \%)$ while the number of subjects using SC or OA increased to $12.4 \%$ and $20.2 \%$, respectively (Figure 2 ). Approximately half the subjects had an oral agent discontinued, most often a secretagogues. In Group 2, the number of subjects using insulin (SC) increased to $58.1 \%$ by Week 52 while the number of subjects using only OA further declined, to $41.9 \%$ (Figure 2).

Among the subjects using SC insulin in both Groups at baseline, $89 \%$ of subjects used a pen device for insulin administration. None used an insulin pump. There was no difference in pen use between the groups. During the study, patients in Group 2 more frequently initiated human analogue long-acting insulin with 99 (27\%) initiating insulin glargine and $40(11 \%)$ initiating insulin detemir compared to Group 1 where $41(12 \%)$ introduced insulin glargine, and $17(5 \%)$ insulin detemir. While more than $90 \%$ of patients used INH without a SC long- or intermediate-acting insulin initially, $24 \%$ had initiated additional SC insulin, usually long-acting, insulin at study end. Of those subjects using SC insulin at study end, 29\% in Group 1 and 36\% in Group 2 were on multiple daily injections combining short- and long-acting insulin preparations. The majority of SC subjects, however, was treated with long-acting insulin and OA (67\% in Group 1, $59 \%$ in Group 2).

\section{Oral agent users}

In both study groups, metformin remained the most common agent with a slight increase comparing baseline and Week 52 (Group 1: 92\%/93\%; Group 2: 92\%/96\%). The overall prescription of secretagogues in both groups decreased although more dramatically in Group 1, which may be related to the greater use of insulin (Figure 3). In both groups the use of sulphonylurea compounds dropped when comparing baseline and Week 26 (Group 1: 79\%/56\%; Group 2: 81\%/66\%) as did glinide use (Group 1: 11.8\%/5.1\%; Group 2: 11.6\%/11.6\%). Similarly, the use of thiazolidinediones (TZDs) was lower in Group 1 at 26 weeks (36\%/19\%) than in Group 2 (35\%/36\%) compared to baseline. Prescription of alpha-glucosidase inhibitors decreased by at least half in both groups compared to baseline (Group 1: 9\%/4\%; Group 2: 8\%/4\%). Other antidiabetic agents were sparsely $(<5 \%)$ prescribed throughout the trial period. 
Table I Baseline patient demographics

\begin{tabular}{|c|c|c|}
\hline & $\begin{array}{l}\text { Group I: Standard therapies } \\
\text { including INH } \mathbf{N}=355\end{array}$ & $\begin{array}{l}\text { Group 2: Standard therapies } \\
\mathbf{N}=372\end{array}$ \\
\hline Mean age \pm SD (range) [years] & $58.7 \pm 9.0(32-78)$ & $58.7 \pm 9.2(37-79)$ \\
\hline Female (\%) & $153(43.1 \%)$ & $164(44.6 \%)$ \\
\hline Mean duration of diabetes (range) [years] & II.I (I.3-45.I) & II.I (I.I-44.3) \\
\hline Mean $A_{I c}$ at screening $\pm S D$ (range) [\%] & $9.3 \pm 1.2(7.9-14.2)$ & $9.2 \pm 1.1(7.3-16.3)$ \\
\hline Mean BMI \pm SD (range) $\left[\mathrm{kg} / \mathrm{m}^{2}\right]$ & $30.9 \pm 4.5(21.5-42.4)$ & $31.1 \pm 4.8(20.6-42.9)$ \\
\hline Mean fasting plasma glucose \pm SD (range) $[\mathrm{mmol} / \mathrm{l}]$ & $\mathrm{II} .7 \pm 2.9(4.0 \mathrm{I}-22.9)$ & $I I . I \pm 2.6(5.3-20.0)$ \\
\hline Mean triglycerides \pm SD (range) [mmol/l] & $2.4 \pm 2.0(0.5-23.1)$ & $2.2 \pm 1.3(0.5-9.7)$ \\
\hline Mean total cholesterol \pm SD (range) $[\mathrm{mmol} / \mathrm{l}]$ & $5 . I \pm I . I(2.6-9.6)$ & $4.9 \pm 1.0(2.1-8.9)$ \\
\hline Mean HDL \pm SD (range) [mmol/l] & $1.3 \pm 0.3(0.5-2.6)$ & $1.3 \pm 0.3(0.4-2.7)$ \\
\hline Mean LDL \pm SD (range) $[\mathrm{mmol} / \mathrm{l}]$ & $2.8 \pm 0.9(0.8-6.6)$ & $2.7 \pm 0.8(0.1-6.0)$ \\
\hline Median systolic BP [mmHg] (IQR) & I35 (|25-|44) & $134.5(\mid 25-145)$ \\
\hline Median diastolic BP [mmHg] (IQR) & $80(73-84)$ & $80(72.1-85)$ \\
\hline Median DTSQ (IQR) & $27(2 I-33)$ & $27(22-32)$ \\
\hline Median EQ-5D & $0.80(0.73-1.00)$ & $0.80(0.73-1.00)$ \\
\hline \multicolumn{3}{|c|}{ Pre-study oral agent combinations* } \\
\hline & $N=347$ & $N=363$ \\
\hline Two oral agent combination & $253(72.9 \%)$ & $266(73.3 \%)$ \\
\hline SU + Met [\%] & $166(47.8 \%)$ & $176(48.5 \%)$ \\
\hline Met + TZD [\%] & $28(8.1 \%)$ & $26(7.2 \%)$ \\
\hline Met + Glinides [\%] & $24(6.9 \%)$ & $28(7.7 \%)$ \\
\hline SU + TZD [\%] & $21(6.1 \%)$ & 17 (4.7\%) \\
\hline Three oral agent combination & 94 (27.1\%) & 97 (26.7\%) \\
\hline SU + Met + TZD [\%] & $56(16.1 \%)$ & $69(19.0 \%)$ \\
\hline SU + Met $+\alpha$-glucosidase inhibitor & $12(3.5 \%)$ & II (3.0\%) \\
\hline
\end{tabular}

Abbreviations: BMI, body mass index; BP, blood pressure; DTSQ, Diabetes Treatment Satisfaction Questionnaire; EQ-5D, EuroQol Questionnaire; HDL, high-density lipoprotein; $\mathrm{INH}$, inhaled human insulin; IQR, interquartile range; LDL, low-density lipoprotein; Met, metformin; SD, standard deviation; SU, sulfonylurea; TZD, thiazolidinediones. Note: *Other two and three oral agents were used but $<3 \%$ of patient population.

Patient-reported outcome data were collected at baseline, at Week 26 and end of study visit using the DTSQ (s, c) and EQ-5D questionnaires. ${ }^{14-17}$ More than $80 \%$ of subjects completed the follow-up questionnaires. There was no difference between groups at Week 26 or Week 52 in the total DTSQc score $(\Delta=0.74,0.52$, respectively; $\mathrm{P}=0.09,0.21$, respectively) or EQ-5D utility score ( $\Delta=0.027 ; \mathrm{P}=0.07$ both times).

\section{Efficacy}

In both groups, $A_{1 c}$ was significantly reduced compared with baseline. The largest reduction from baseline in A1c was established in Group $1(-2.0 \% \pm 1.2 \%)$ at Week 12 and in Group $2(-1.8 \% \pm 1.3 \%)$ at Week 26. In both groups, these levels of $A_{1 c}$ reduction were maintained thereafter up to study end, albeit not always statistically significant (Table 2). When assessing efficacy based on a categorical variable, ie, percent of subjects achieving an $\mathrm{A}_{1 \mathrm{c}}$ of less than $7 \%$, the results were similarly in favor of Group 1 (Table 2).
In both groups, fasting plasma glucose was significantly reduced but there was no difference $(P=0.20)$ between the groups despite the less frequent use of long- or intermediate acting insulin (29\% vs 61\%) used in Group 1: Group 1: $57.2 \pm 61.0 \mathrm{mg} / \mathrm{dl}(3.2 \pm 3.4 \mathrm{mmol} / \mathrm{l})$; Group 2: $57.0 \pm 60.6 \mathrm{mg} / \mathrm{dl}$ $(3.2 \pm 3.4 \mathrm{mmol} / \mathrm{l})$. Fasting blood lipid levels also decreased in both groups. Total cholesterol declined by $0.26 \pm 0.84 \mathrm{mmol} / \mathrm{L}$ in Group 1 and $0.17 \pm 0.90 \mathrm{mmol} / \mathrm{L}$ in Group 2. Similarly, triglyceride levels were reduced in both groups (Group 1: $0.54 \pm 1.46 \mathrm{mmol} / \mathrm{L}$; Group 2: $0.51 \pm 1.03 \mathrm{mmol} / \mathrm{L}$ ).

Body weight increased in both groups from baseline (Group 1: $+2.2 \pm 4.8 \mathrm{~kg}$; Group 2: $+2.1 \pm 4.9 \mathrm{~kg}$ ). The adjusted weight difference between groups was $0.02 \mathrm{~kg}$ $(\mathrm{P}=0.95)$ and appeared to be driven by insulin use in both groups (INH: $+2.6 \pm 4.6 \mathrm{~kg}$; SC insulin, Group 1 and 2 combined: $+2.7 \pm 4.8 \mathrm{~kg}$ ) whereas subjects remaining on oral agents had smaller or no weight changes (Group 1 and 2 combined: OA added: $+1.0 \pm 5.5 \mathrm{~kg}$; OA unchanged : $+0.2 \pm 4.7 \mathrm{~kg}$ ). 


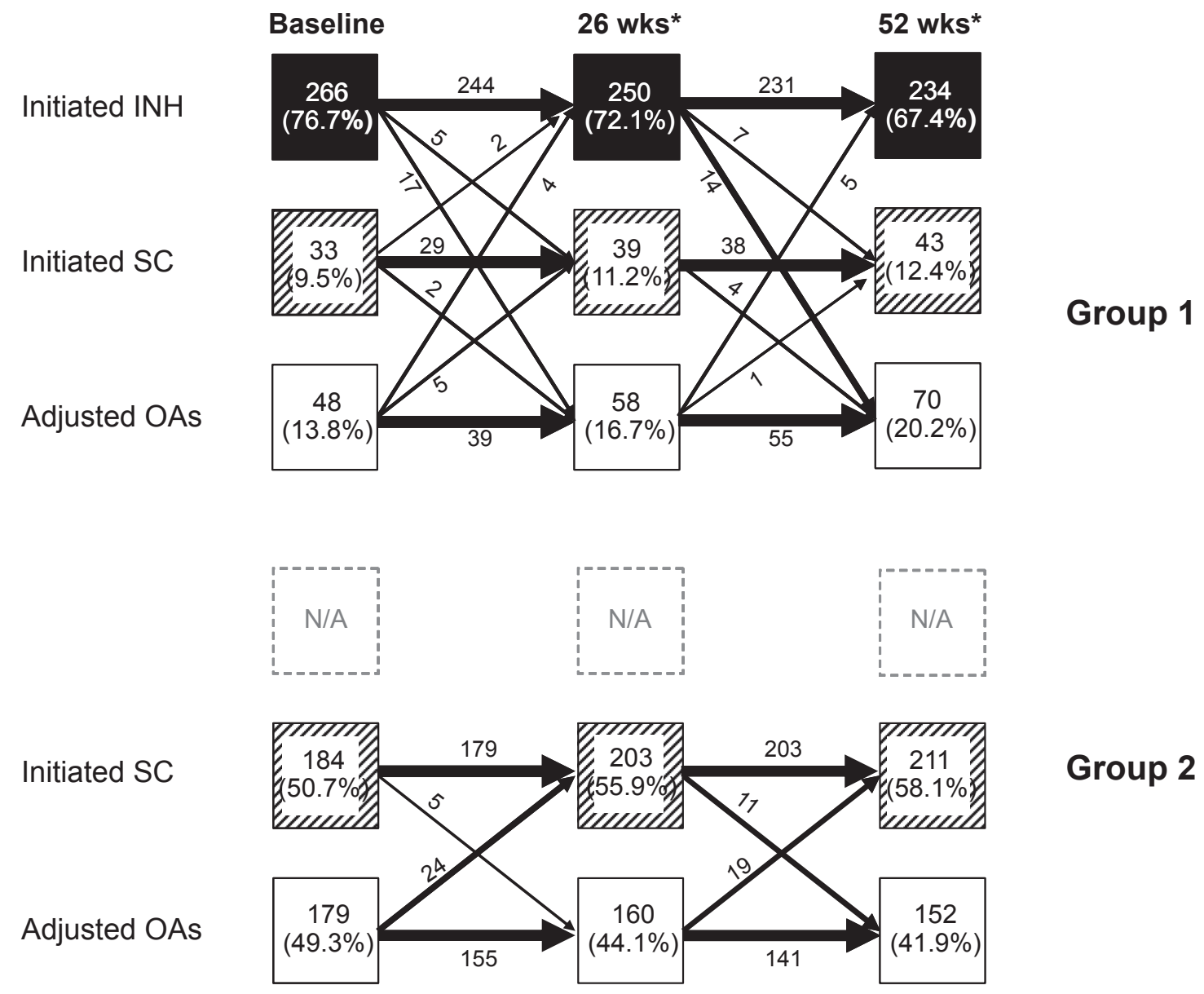

Figure 2 Patient fluxes between major treatment modalities over the one-year study period in Group I (upper panel) and Group 2 (lower panel). Treatments could be changed (adding, deleting pharmaceutical interventions) for safety reasons at any time, for lack of efficacy every three months, and for any reason including inconvenience, at six months.

Note: *Numbers represent choices after completion of the visit.

\section{Safety}

Seventy nine percent of subjects in Group 1 and $70 \%$ of subjects in Group 2 reported at least one treatment-emergent adverse event. Amongst serious adverse events, 3 subjects in Group 2 and 2 subjects in Group 1, respectively, were diagnosed with neoplasms (Table 3). In Group 1, four subjects using INH discontinued therapy for reduction in pulmonary function by more than $15 \%$ (2), dyspnea (1) and cough (1). Other frequently-reported adverse events that were more frequently reported in Group 1 compared to Group 2 included increased cough, pharyngitis and upper respiratory tract infection.

Hypoglycemia was reported in 176 subjects in Group 1 (51\%) and 132 subjects in Group 2 (36\%). 1000/1007 (Group 1: 99.3\%) and 624/626 (Group 2: 99.7\%) of hypoglycemic episodes were classified as 'mild-moderate'. Severe hypoglycemia occurred in 7 subjects in Group 1 and in two subjects in Group 2. Overall, hypoglycemia rates were markedly higher in Group 1 during the first 4-8 weeks compared to
Group 2. In both groups, rates declined over time and were of similar magnitude from Weeks 12 on until end of the trial: $0.1-0.2$ events/subject month.

In either group, there were no significant differences in $\mathrm{FEV}_{1}$ (mean $\left.\pm \mathrm{SD}\right)$ from baseline $(2.75 \pm 0.72 \mathrm{~L}$ in both groups) to Week 52 (Group 1: $2.71 \pm 0.74 \mathrm{~L}$; Group 2: $2.73 \pm 0.71 \mathrm{~L}$ ), or mean DLco (mean $\pm \mathrm{SD}$ ) from baseline (Group 1: $23.9 \pm 6.0$ Group 2: $23.7 \pm 5.7 \mathrm{ml} / \mathrm{min} / \mathrm{mmHg})$ to Week $52(23.4 \pm 6.5$, $23.5 \pm 6.1 \mathrm{ml} / \mathrm{min} / \mathrm{mmHg}$, respectively).

At 52 weeks, significantly more (88\%) subjects on INH had measurable ( $>3 \%$ binding) insulin antibody titers than subjects on SC insulin (33\%) or on oral agents (1\%).

\section{Discussion}

In the EXPERIENCE trial, INH accelerated adoption of insulin and marked improvement in glycemic control at six months, but not at one year. The reduction of $A_{1 c}$ in both groups may be due in part to the high average $\mathrm{A}_{1 \mathrm{c}}$ at baseline 
(the protocol required $\mathrm{A}_{1 \mathrm{c}}$ to be at least $8.0 \%$ at screening). However, subjects continuing oral agents alone also improved their $\mathrm{A}_{\mathrm{lc}}$ by approx $1.5 \%$.

Despite higher hypoglycemia rates, especially at the beginning of the trial, and the need to perform with increased frequency glucose self-monitoring and additional pulmonary consults, most subjects remained on inhaled insulin up to the end of the study even when additional SC long-acting insulin became necessary to control glycemia.

Consistent with prior clinical experience, other side effects were limited to irritation of the upper respiratory tract (increased cough, pharyngitis), and increased anti insulin antibody titers. Two subjects discontinued INH because of changes in lung function.

There was reduced prescription of oral agents (sulfonylurea [SU] and TZD drugs; Figure 3) and long-acting insulin preparations in Group 1 compared to Group 2. Control of fasting glucose remained good in INH subjects even without co-prescription of long-acting insulin despite the short-acting pharmacokinetic profile of INH. This confirms that the pharmacodynamic action of INH may differ from short-acting $\mathrm{SC}$ insulin as already observed in previous preclinical and clinical studies ${ }^{18-20}$ and include a longer duration of action than anticipated based on pharmacokinetic data. The reasons remain elusive at this time and await elucidation by further studies.
Commensurate with improvement of glycemic control, lipid levels improved in both groups significantly from baseline, particularly in those subjects using insulin whether inhaled or injected. The modest difference in glycemic control established early on in the study narrowed towards the end, possibly because some patients in Group 1 returned to oral agent therapy while patients in Group 2 continued to adopt insulin albeit at a slow pace. The reasons for some subjects to return to oral agent after initially having chosen insulin (inhaled or SC) is not known. In Group 1, that number was higher (31 subjects or $12 \%$ from INH, 6 subjects or $18 \%$ ) from SC, altogether 47 subjects or 16\%) compared to Group 2 (16 subjects or $9 \%$ ) but this result may have also been influenced by the slower adoption of insulin in Group 2 which remained well below that of Group 1 at Week 52. The absence of "forced" compliance with treatment targets may have contributed to reduced insulin use late in the study when improvements in glycemic control brought about by insulin no longer outweighed the downsides as convincingly as at the beginning of the study.

The EXPERIENCE study showed that, in both study arms, subjects chose insulin at a high rate leading to a marked fall in $A_{1 c}$. This may be viewed as a surprising outcome but the nature of the study intervention may explain this unexpected result. To mimic as closely as possible "real life", we used an open label study design which allowed both study subjects and physicians to express personal preferences by freely choosing among
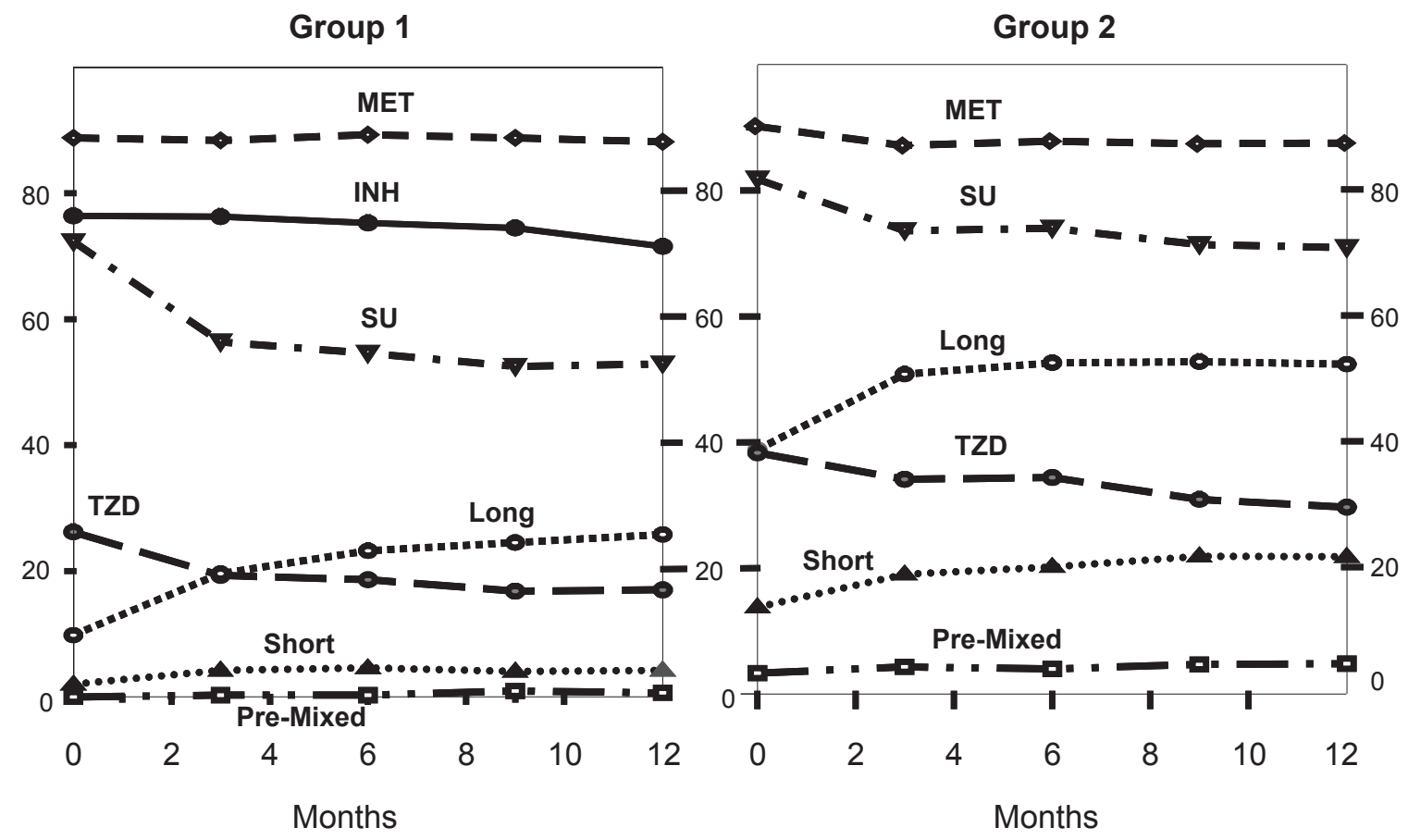

Figure 3 Change in use frequency (\%) of antidiabetic drugs. 
Table 2 Primary and secondary efficacy endpoints

\begin{tabular}{|c|c|c|c|}
\hline Efficacy variable & $\begin{array}{l}\text { Group I: Standard therapies } \\
\text { including INH; } \mathbf{N}=355\end{array}$ & $\begin{array}{l}\text { Group 2: Standard therapies; } \\
\mathbf{N}=372\end{array}$ & $\begin{array}{l}P \text { value for difference } \\
\text { between groups }\end{array}$ \\
\hline \multicolumn{4}{|l|}{$\begin{array}{l}\text { Change from baseline in mean } A_{I c} \text { from } \\
\text { baseline } \pm S D[\%] \text { at }\end{array}$} \\
\hline 4 weeks & $-1.1 \pm 0.8$ & $-0.9 \pm 0.9$ & 0.0008 \\
\hline 12 weeks & $-2.0 \pm 1.1$ & $-1.6 \pm 1.2$ & $<0.0001$ \\
\hline 26 weeks & $-2.0 \pm 1.2$ & $-1.8 \pm 1.3$ & 0.0030 \\
\hline 34 weeks & $-2.1 \pm 1.2$ & $-1.8 \pm 1.2$ & 0.0011 \\
\hline 42 weeks & $-2.0 \pm 1.2$ & $-1.8 \pm 1.3$ & 0.1523 \\
\hline 52 weeks & $-2.0 \pm 1.2$ & $-1.8 \pm 1.3$ & 0.0491 \\
\hline 52 weeks (LOCF) & $-1.9 \pm 1.2$ & $-1.8 \pm 1.3$ & 0.2251 \\
\hline \multicolumn{4}{|l|}{ Percent subjects with $A_{I c}$ less than $7 \%$ at } \\
\hline 4 weeks & 9.1 & 4.0 & 0.0027 \\
\hline 12 weeks & 40.2 & 29.6 & 0.0004 \\
\hline 26 weeks & 47.5 & 41.5 & 0.0315 \\
\hline 34 weeks & 48.5 & 38.9 & 0.0023 \\
\hline 42 weeks & 42.2 & 38.7 & 0.1990 \\
\hline 52 weeks & 44.7 & 40.4 & 0.1424 \\
\hline 52 weeks (LOCF) & 41.8 & 39.4 & 0.2190 \\
\hline $\begin{array}{l}\text { Change from baseline in fasting plasma } \\
\text { glucose } \pm \text { SD ( } \mathrm{mmol} / \mathrm{l}) \text { at } 52 \text { weeks }\end{array}$ & $-3.2 \pm 3.4$ & $-3.2 \pm 3.4$ & 0.2007 \\
\hline $\begin{array}{l}\text { Change from baseline in mean } \\
\text { triglycerides } \pm \mathrm{SD}(\mathrm{mmol} / \mathrm{l}) \text { at } 52 \text { weeks }\end{array}$ & $-2.6 \pm 2.8$ & $-2.8 \pm 2.9$ & 0.5740 \\
\hline $\begin{array}{l}\text { Change from baseline in mean total } \\
\text { cholesterol } \pm \mathrm{SD}(\mathrm{mmol} / \mathrm{l}) \text { at } 52 \text { weeks }\end{array}$ & $-4.7 \pm 18.8$ & $-3.3 \pm 18.1$ & 0.7006 \\
\hline $\begin{array}{l}\text { Change from baseline in mean } \\
\mathrm{HDL} \pm \mathrm{SD}(\mathrm{mmol} / \mathrm{l}) \text { at } 52 \text { weeks }\end{array}$ & $+0.5 \pm 3.7$ & $+1.0 \pm 4.3$ & 0.4190 \\
\hline $\begin{array}{l}\text { Change from baseline in mean } \\
\mathrm{LDL} \pm \mathrm{SD}(\mathrm{mmol} / \mathrm{l}] \text { at } 52 \text { weeks }\end{array}$ & $-0.8 \pm 13.9$ & $+0.7 \pm 14.4$ & 0.3203 \\
\hline
\end{tabular}

Abbreviations: HDL, high-density lipoprotein; INH, inhaled human insulin; LDL, low-density lipoprotein; LOCF, last observation carried forward; SD, standard deviation. Notes: LOCF included subjects that had discontinued before the 52 Week visit: 347 (Group I) and 363 (Group 2) subjects vs 302 and 324 subjects, respectively, completing the study at 52 weeks.

available treatments. In conventional controlled trials, subjects may decline to consent because of their a priori preferences for one of the treatments, or their outcomes may be worse because of poor adherence or a negative placebo-like effect. ${ }^{21}$

Whether intermittent insulin therapy in certain patient groups may achieve acceptable long-term control of diabetes is certainly an intriguing aspect of this trial that may warrant further research. Previous studies were not encouraging but were of limited size and duration..$^{22,23}$

Assessment of attitudes of health care professionals and patients towards new technologies is important to the extent that these attitudes may influence appropriate uptake. The purpose of the EXPERIENCE trial was to address the potential increased acceptability of making inhaled insulin available compared with conventional injectable insulins, aiming to incorporating patients and physician choice which is commonly "designed out" in conventional randomized trials. One potential limitation of a randomized trial design in this context is that subjects may not be representative of clinical practice but patients may self select to be those ready to make changes to their management in order to achieve improved glycaemic control. This appeared to be a feature of the EXPERIENCE trial where uptake of insulin was substantially higher in the control group than that observed in observational studies ${ }^{24}$ where median time from initiation of last oral therapy to insulin uptake was almost eight years in an unselected cohort of mostly poorly controlled subjects. Further the questionnaire-based feasibility study ${ }^{13}$ conducted only three years prior to the EXPERIENCE trial, in largely different study centers, and including some patients taking less than two oral agents, which was undertaken to help estimate sample size for 
Table 3 Adverse events and hypoglycemia in the EXPERIENCE trial

\begin{tabular}{|c|c|c|c|c|c|}
\hline \multicolumn{6}{|l|}{ Adverse events } \\
\hline & \multicolumn{2}{|c|}{ Group I } & \multicolumn{2}{|c|}{ Group 2} & \multirow[b]{2}{*}{$P$ value } \\
\hline & $\mathbf{n}$ & $\%$ & $\mathbf{n}$ & $\%$ & \\
\hline Cardiovascular & 35 & 8 & 53 & 14.2 & 0.07 \\
\hline Respiratory overall & 144 & 40.3 & 96 & 25.7 & $<0.001$ \\
\hline Cough & 51 & 14.3 & 18 & 4.8 & $<0.001$ \\
\hline Pharyngitis & 47 & 13.2 & 36 & 9.7 & 0.05 \\
\hline URTI & 34 & 9.5 & 26 & 7.0 & 0.21 \\
\hline Dyspnea & 6 & 1.7 & 2 & 0.5 & 0.16 \\
\hline Lung cancer* & 1 & 0.3 & 0 & 0 & 0.49 \\
\hline Other neoplasms** & 2 & 0.6 & 3 & 0.7 & 0.72 \\
\hline \multicolumn{6}{|l|}{ Hypoglycemia } \\
\hline Number of subjects with $\geq I$ event & 176 & 49.3 & 134 & 35.9 & 0.02 \\
\hline $\begin{array}{l}\text { Number of subjects with severe } \\
\text { hypoglycemia }\end{array}$ & 7 & 2.0 & 2 & 0.5 & 0.10 \\
\hline Crude event rate per subject month & 0.25 & & 0.15 & & NA \\
\hline $\begin{array}{l}\text { Crude event rate per subject month } \\
\text { between Week } 26 \text { and Week } 52\end{array}$ & 0.15 & & 0.13 & & NA \\
\hline
\end{tabular}

Abbreviation: URTI, upper respiratory tract infection.

Notes: *Subject with pre-trial smoking history; **Group I: prostate, skin; Group 2: T-cell lymphoma, pancreas, breast.

the present study indicated a much lower willingness to adopt insulin (including inhaled insulin). Nonetheless, the feasibility study helped to estimate the influence the proportional impact of choice differences on glycemic outcomes. As a result, even the small differences seen in the present study were statistically significant although their clinical relevance may be uncertain.

On average subjects experienced substantial benefits in improved glycaemic control regardless of their therapy, and despite the increased uptake of insulin in the INH group, there was considerable dilution of the effect as both groups represent a mix of different treatment modalities. Although most subjects remained on their initially-chosen "lead" treatment, eg, inhaled or SC insulin, many had concurrent treatment changed, be it to reduce hypoglycemia or improve overall efficacy, just as commonly practiced outside clinical trials. Thus, in the absence of similarly-designed studies it is difficult to estimate how relevant the observed differences are. Furthermore, the trial showed that freedom to select the most appropriate (based on the physician's and subject's opinion) treatment reduces differences between treatment modalities compared to data generated by conventionallydesigned head-to-head trials.

An obvious limitation of the EXPERIENCE trial is that it failed to corroborate the adoption of Exubera inhaled insulin in clinical practice. ${ }^{25}$ This points to a further potential limitation of the EXPERIENCE trial, in that physicians may have self selected to have become investigators based upon a raised willingness to use inhaled insulin, and in particular this delivery system which may have been less appealing to many of their colleagues, maybe as a result of size or complexity of the delivery system which can significantly influence the selection of therapeutics. ${ }^{26,27}$ Self-selection of both physicians and patients for clinical studies challenges the external validity of trials using designs such as this, although it remains highly desirable to have estimates of treatment effect based upon randomized trials. Thus further steps may be required to translate estimates of the relative uptake of insulin therapy in randomized trials into their likely consequences in populations of clinicians and patients that better reflect clinical practice.

In conclusion, the EXPERIENCE trial showed that novel delivery technology can accelerate the adoption of insulin although some attenuation of differences is observed over time. And further, that this was achieved in a population of patients who appeared more ready to move to insulin therapy than observed in standard clinical practice, and a group of physicians who appeared more ready to adopt INH than the majority of physicians.

\section{Disclosure}

This study was sponsored by Pfizer Inc. 


\section{References}

1. Hogan P, Dall T, Nikolov P. Economic costs of diabetes in the US in 2002. Diabetes Care. 2003;26:917-932.

2. Klein R, Klein BE, Moss SE, Cruickshanks KJ. The Wisconsin Epidemiologic Study of Diabetic Retinopathy. XV. The long-term incidence of macular edema. Ophthalmology. 1995;102:7-16.

3. Ohkubo Y, Kishikawa H, Araki E, et al. Intensive insulin therapy prevents the progression of diabetic microvascular complications in Japanese patients with non-insulin-dependent diabetes mellitus: a randomized prospective 6-year study. Diabetes Res Clin Pract. 1995;28:103-117.

4. Intensive blood-glucose control with sulphonylureas or insulin compared with conventional treatment and risk of complications in patients with type 2 diabetes (UKPDS 33). UK Prospective Diabetes Study (UKPDS) Group. Lancet. 1998;352:837-853.

5. de Sonnaville JJ, Snoek FJ, Colly LP, Devillé W, Wijkel D, Heine RJ. Well-being and symptoms in relation to insulin therapy in type 2 diabetes. Diabetes Care. 1998;21:919-924.

6. Martinez L, Consoli SM, Monnier L, et al. Studying the Hurdles of Insulin Prescription $\left(\mathrm{SHIP}^{\odot}\right)$ : development, scoring and initial validation of a new self-administered questionnaire. Health Qual Life Outcomes. 2007;5:53.

7. Peyrot M, Rubin RR, Lauritzen T, et al. Resistance to insulin therapy among patients and providers: results of the cross-national Diabetes Attitudes, Wishes, and Needs (DAWN) study. Diabetes Care. 2005;28:2673-2679.

8. Horne R, Weinman J, Barber N, Elliott RA, Morgan M. Concordance, Adherence and Compliance in Medicine Taking: A conceptual map and research priorities. London, UK: National Co-ordinating Centre for NHS Service Delivery and Organisation, NCCSDO; 2005.

9. Cappelleri JC, Cefalu WT, Rosenstock J, Kourides IA, Gerber RA. Treatment satisfaction in type 2 diabetes: a comparison between an inhaled insulin regimen and a subcutaneous insulin regimen. Clin Ther. 2002;24:552-564.

10. Freemantle N, Blonde L, Bolinder B, et al. Real-world trials to answer real-world questions. Pharmacoeconomics. 2005;23:747-754.

11. Freemantle N, Strack TR; the Real World Trialists. Will availability of inhaled human insulin $\left(\right.$ Exubera $\left.^{\circledR}\right)$ improve management of type 2 diabetes? The design of the Real World Trial. Trials. 2006;7:25.

12. Del Prato S, Blonde L, Martinez L, et al; EXPERIENCE Trial Team. The effect of the availability of inhaled insulin on glycaemic control in patients with type 2 diabetes failing on oral therapy: the evaluation of Exubera as a therapeutic option on insulin initiation and improvement in glycaemic control in clinical practice (EXPERIENCE) trial. Diabet Med. 2008;25:662-670.
13. Freemantle N, Blonde L, Duhot D, et al. Availability of inhaled insulin promotes greater perceived acceptance of insulin therapy in patients with type 2 diabetes. Diabetes Care. 2005;28:427-428.

14. Bradley C. The Diabetes Treatment Satisfaction Questionnaire: DTSQ. In: Bradley $\mathrm{C}$, editor. Handbook of Psychology and Diabetes: a guide to psychological measurement in diabetes research and practice. Chur, Switzerland; Harwood Academic Publishers, 1994. p. 111-132.

15. Plowright R, Witthaus E, Bradley C. Psychometric evaluation of the Diabetes Treatment Satisfaction Questionnaire in 8 languages. $\mathrm{Proc} \mathrm{Br}$ Psychol Soc. 2000;8:43.

16. The EuroQol Group. EuroQol - a new facility for the measurement of health-related quality of life. Health Policy. 1990;16:199-208.

17. Brooks R. EuroQol: the current state of play. Health Policy. 1996; 37:53-72.

18. Strack TR. Inhaled human insulin. Drugs Today. 2006;42:207-221.

19. Edgerton DS, Cherrington AD, Neal DW, et al. Inhalation of insulin (Exubera $^{\mathbb{R}}$ ) augments the efficiency of muscle glucose uptake in vivo. Diabetes. 2006;55:3604-3610.

20. Edgerton DS, Stettler KM, Neal DW, et al. Inhalation of human insulin is associated with improved insulin action compared with subcutaneous injection and endogenous secretion in dogs. J Pharmacol Exp Ther. 2006;319:1258-1264

21. King M, Nazareth I, Lampe F, et al. Impact of participant and physician intervention preferences on randomized trials: a systematic review. JAMA. 2005;293:1089-1099.

22. Yki Jarvinen H, Esko N, Eero H, Marja Riitta T. Clinical benefits and mechanisms of a sustained response to intermittent insulin therapy in type 2 diabetic patients with secondary drug failure. $\mathrm{Am} \mathrm{J} \mathrm{Med}$. 1988;84:185-192.

23. Groop L, Widen E. Treatment strategies for secondary sulfonylurea failure. Should we start insulin or add metformin? Is there a place for intermittent insulin therapy? Diabetes Metab. 1991;17:218-223.

24. Calvert MJ, McManus RJ, Freemantle N. Management of type 2 diabetes with multiple oral hypoglycaemic agents or insulin in primary care: retrospective cohort study. Br J Gen Pract. 2007;57:455-460.

25. Mack GS. Pfizer dumps Exubera. Nature Biotechnol. 2007;25:1331-1332.

26. Gustafsson P, Taylor A, Zanen P, Chrystyn H. Can patients use all dry powder inhalers equally well? Int J Clin Pract. 2005;149(Suppl): 13-18.

27. Ahonen A, Leinonen M, Ranki-Pesonen M. Patient satisfaction with Easyhaler ${ }^{\mathbb{B}}$ compared with other inhalation systems in the treatment of asthma. Curr Ther Res Clin Exp. 2000;61:61-73. 